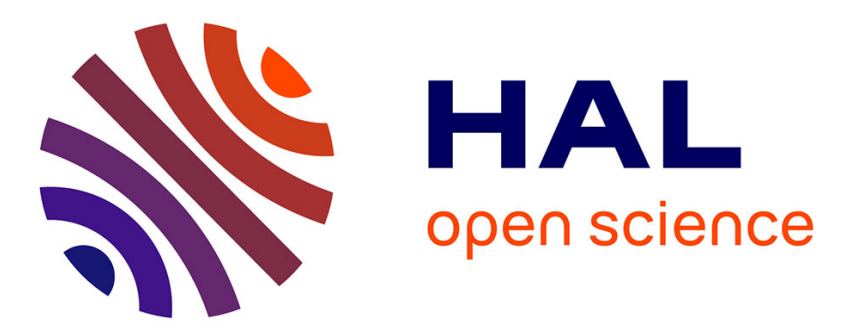

\title{
Simulation and Visualization of Thermal Metaphor in a Virtual Environment for Thermal Building Assessment
}

\author{
Yudi Nugraha Bahar, Jérémie Landrieu, Christian Père, Christophe Nicolle
}

\section{To cite this version:}

Yudi Nugraha Bahar, Jérémie Landrieu, Christian Père, Christophe Nicolle. Simulation and Visualization of Thermal Metaphor in a Virtual Environment for Thermal Building Assessment. International Journal of Technology, 2014, 5 (1), pp.3-13. 10.14716/ijtech.v5i1.148 . hal-01097520

\section{HAL Id: hal-01097520 \\ https://hal.science/hal-01097520}

Submitted on 19 Dec 2014

HAL is a multi-disciplinary open access archive for the deposit and dissemination of scientific research documents, whether they are published or not. The documents may come from teaching and research institutions in France or abroad, or from public or private research centers.
L'archive ouverte pluridisciplinaire HAL, est destinée au dépôt et à la diffusion de documents scientifiques de niveau recherche, publiés ou non, émanant des établissements d'enseignement et de recherche français ou étrangers, des laboratoires publics ou privés. 


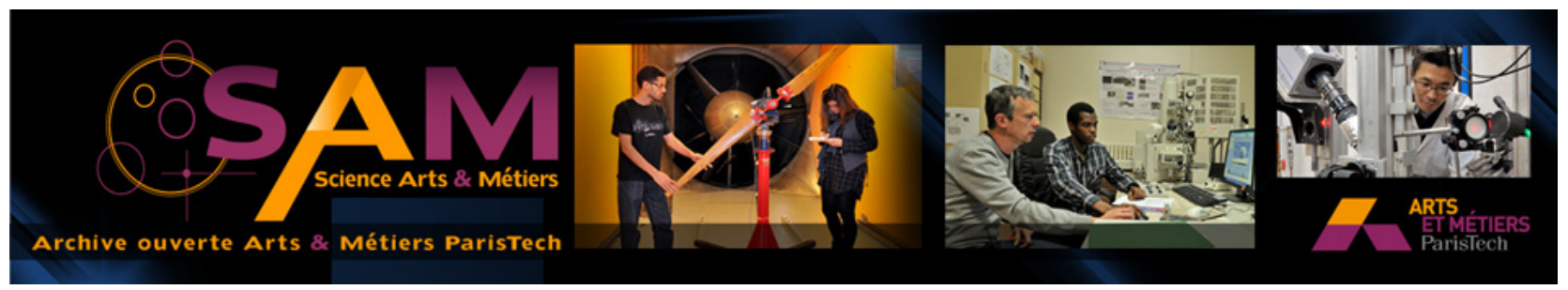

\section{Science Arts \& Métiers (SAM)}

is an open access repository that collects the work of Arts et Métiers ParisTech researchers and makes it freely available over the web where possible.

This is an author-deposited version published in: http://sam.ensam.eu

Handle ID: .http://hdl.handle.net/10985/9135

\section{To cite this version :}

Yudi NUGRAHA BAHAR, Jérémie LANDRIEU, Christian PÈRE, Christophe NICOLLE -

Simulation and Visualization of Thermal Metaphor in a Virtual Environment for Thermal Building Assessment - International Journal of Technology - Vol. 5, n¹, p.3-13 - 2014 


\title{
SIMULATION AND VISUALIZATION OF THERMAL METAPHORS IN A VIRTUAL ENVIRONMENT FOR THERMAL BUILDING ASSESSMENT
}

\author{
Yudi Nugraha Bahar ${ }^{* 1,2}$, Jérémie Landrieu ${ }^{1}$, Christian Pere $^{1}$, Christophe Nicolle ${ }^{2}$ \\ ${ }^{1}$ Arts et Metiers ParisTech, UMR CNRS 6306, LE2I, Institut Image, Chalon-sur-Saône, France \\ ${ }^{2}$ Université de Bourgogne, Laboratoire LE2I, UMR CNRS 6306, Dijon Cedex, France
}

\begin{abstract}
The current application of the design process through energy efficiency in virtual reality (VR) systems is limited mostly to building performance predictions, as the issue of the data formats and the workflow used for 3D modeling, thermal calculation and VR visualization. The importance of energy efficiency and integration of advances in building design and VR technology have lead this research to focus on thermal simulation results visualized in a virtual environment to optimize building design, particularly concerning heritage buildings. The emphasis is on the representation of thermal data of a room simulated in a virtual environment (VE) in order to improve the ways in which thermal analysis data are presented to the building stakeholder, with the aim of increasing accuracy and efficiency. The approach is to present more immersive thermal simulation and to project the calculation results in projective displays particularly in Immersion room (CAVE-like). The main idea concerning the experiment is to provide an instrument of visualization and interaction concerning the thermal conditions in a virtual building. Thus the user can immerge, interact, and perceive the impact of the modifications generated by the system, regarding the thermal simulation results. The research has demonstrated it is possible to improve the representation and interpretation of building performance data, particularly for thermal results using visualization techniques.
\end{abstract}

Keywords: Building performance; Thermal metaphor; Virtual environment

\section{INTRODUCTION}

Thermal simulation has the potential to improve quality and energy efficiency in the building. The integration of CAD and VR techniques in the development of thermal simulations brings new perspectives to evaluate the design process. These building energy simulation models give building stakeholders a cost-effective tool to simulate the energy result of a building. The VR technique used since it becomes an important support in the building performance domain, as it enables the rapid and intuitive exploration of the 3D volume containing the data and provide a high quality, immersive visual representation of virtual prototypes (Bruno et al., 2008; Gutierrez et al., 2008). A particular approach of the environment used to display temperature data was conducted by adding thermal data objects into the VE. This is to reconstruct the thermal pre-computed data by activating thermal objects surrounding the room in time variable and convert the data into the VR system. As a visualization tool, VR has the potential of giving users a less inhibited method of observing and interacting with data. By placing users in the same environment as the data, a better sense of shape, motion, and spatial relationship can be conveyed (Clifton et al., 1997). 
Several studies have been conducted to represent thermal building simulation results in VE. Fricoteaux (2010) has studied the creation of thermal Information in VE called Thermic3D. He proposes different solutions to retrieve information regarding thermal data and re-transcribes thermal calculation results in a virtual building. The experiment made some excellent progresses concerning solution on perception of thermal data and especially visual and thermal feedback in VE. However, problems in representing details of the thermal calculation results in 3D volumetric with friendly interface remain. Van Treeck et al. (2006) presented the work on the development of an interactive computational steering environment (CSE) for interactive indoor thermal comfort simulation by utilizing high-performance supercomputing facilities. They integrated an interactive user interface with a context-based 3D menu to provide an intuitive front-end in the application. The approach to thermal visualization concept is very comprehensive. However, the calculation only focused on single task simulation and the interface was not considered for immersive sensation.

Malkawi et al. (2005) have worked on an interactive speech and gesture recognition-based, immersive Augmented Reality (AR) model designed to visualize and interact with buildings and their thermal environments. The thermal metaphors presented were colored fluid dynamics and particles in isoplane through HMD. However, while projected in VE, the user is still burdened with the number of sensors and other heavy equipment.

As can be seen from the previous projects, thermal simulation and visualization using a metaphor have been applied in a number of VR applications. However, no previous work compared thermal metaphors to visual conditions in a realistic CAVE task. In addition, their VE is less similar to the real environment. This could lead to misinterpretation of the user, and they are complicated in workflow. Therefore, it is necessary to find out the method applicable for seamless workflow that takes into account the nature of the data and the characteristics of the human perceptual system. These are the areas that we are addressing in this paper.

\section{METHODOLOGY/ EXPERIMENTAL}

\subsection{Thermal Building Simulation in the Context of this Study}

Building thermal simulation is a powerful method for studying the thermal performance of buildings and to evaluate architectural design. Complex design problems can be investigated and their performance can be quantified and evaluated. From an AEC (ArchitectureEngineering-Construction) perspective, advanced analysis of building thermal simulation in building modeling programs has become a critical part of high-performance buildings. The conceptual design phase of thermal modeling is used to provide the designer with first order of magnitude feedback about the impact of various building configuration on annual thermal performance (US GSA, 2010).

Mean radiant temperature (MRT) is a primary factor and should be identified as having the strongest effect of thermal comfort. MRT is simply the area weighted mean temperature of all the objects surrounding the body. The MRT is a significant factor, especially in buildings whose outer walls were exposed to a strong solar radiation, and where conventional indoor temperature and humidity control cannot guarantee indoor comfort (Atmaca et al., 2006). The radiant temperature can be calculated from measured values of the temperature of the surrounding walls and surfaces and their positions with respect to the person (Bean, 2010). Effects of radiant temperature on human thermal comfort of MRT are conducted for this experiment. Ecotect thermal analysis provides an optimistic method for this calculation. As performed in Ecotect, Humphreys et al. (1998) give equations for calculating the indoor comfort temperature from outdoor monthly mean temperature as follows.

Free Running Building: 


$$
\mathrm{T}_{\mathrm{c}}=11.9+0.534 \mathrm{~T}_{\mathrm{o}}
$$

Heated or Cooled Building:

$$
\mathrm{T}_{\mathrm{C}}=23.9+0.295\left(\mathrm{~T}_{0}-22\right) \exp \left(\left[-\left(\mathrm{T}_{0}-22\right) / 33.941\right]^{2}\right)
$$

\subsection{Object of Experiment}

The experiment began with the background checking of the object, the realization of a mock-up model of the existing conditions, followed by the exploration for some alternative models (renovated version scenario). The Gunzo room was chosen as the object of the experiment as representatives of other rooms in the building. The room is located in an old building situated on the historical site of the Cluny Abbey which is also a part of Arts et Métiers ParisTech (ENSAM) campus. The room volume is approximately $68.5 \mathrm{~m}^{3}$ (length $4.45 \mathrm{~m}$, width $3.93 \mathrm{~m}$, and height $3.92 \mathrm{~m}$ ). The stone wall is $85 \mathrm{~cm}$ thick, and the doors and window are made of wood. As it is typical of old structures, the building consists of rooms enclosed by thick walls and large windows which have been protected. Thermal problems exist in all of the rooms, so it can be quite uncomfortable for the occupants. In this case, we found that the window was the most crucial factor effecting indoor energy consumption. The interior configuration is adapted to the addition of a partition surmounted for a new window. This concept is used as part of an interior insulation of a building (TerMinassian, 2011) which has demonstrated its effectiveness, and is becoming common practice in window renovation especially in the Nordic countries.

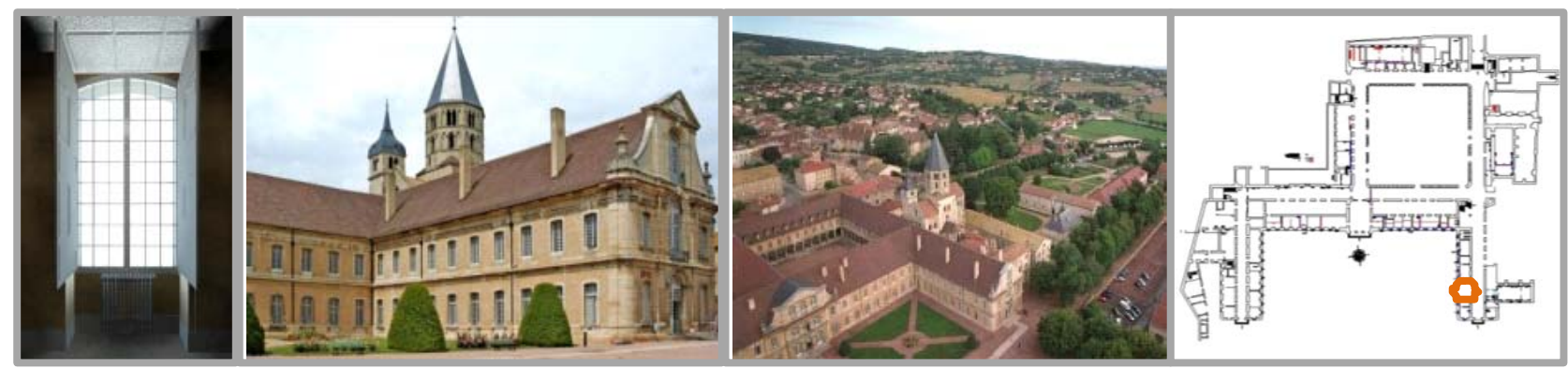

Figure 1 Gunzo room in Revit digital mock-up (left). The object located in historical site of Cluny

We operated a modification on the interior shutter in terms of its position as well as its material. The modification was effected by moving the interior shutter backwards against the exterior sash. This modification required the addition of a shelf under the window sill.

(a)
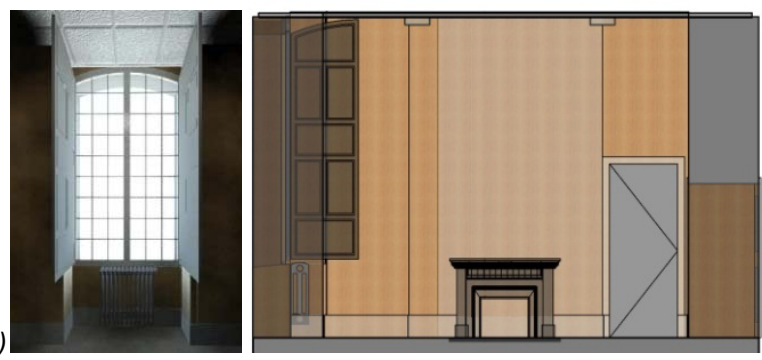

(b)
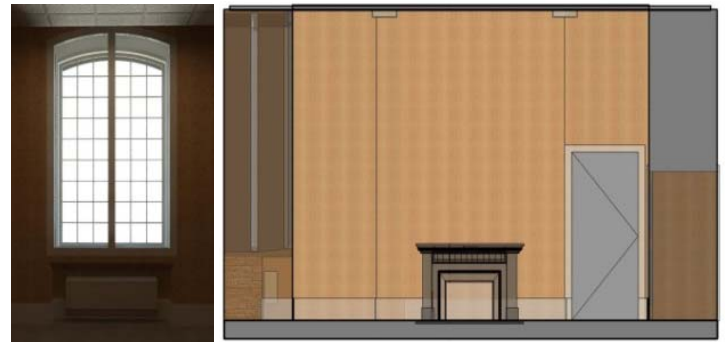

Figure 2 (a) Revit Model of Gunzo room (3D View and section) in existing conditions; (b) Renovated version, changes made to the wall, window components and heater

\subsection{Monthly Temperature Profile}

In this calculation, the weather data files in Ecotect are taken from the US Department of Energy (EERE, 2012), arranged by World Meteorological Organization region and Country. It provides data based on weather factors (solar, wind, temperature, etc.) referenced per year. The 
monthly temperature graph displays the internal temperatures of the Gunzo room thermal zone over a one-year period as measured by Ecotect. These data are based on the average daily maximum and minimum temperatures, for each month and as an annual statistic, and preformatted into a 3D entity, transferred and visualized in VE.

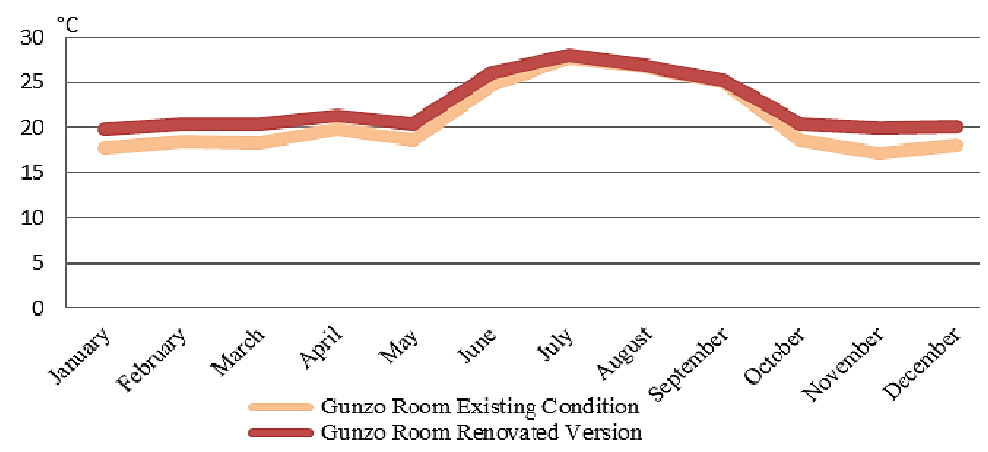

Figure 3 Monthly mean radiant temperature results between the two versions of the Gunzo room during the year

\subsection{Modeling Techniques and VR Interactive System}

The uses of VR models have provided the potential to increase the performance and reliability of the information (Woksepp et al., 2006). However, most of VR software is focused only on visualization of movement simulation, animation and visual effects. As VR software does not provide particular technical thermal calculations, interoperability between used tools required is with a specific workflow. In order to conduct seamless data exchange, it is important to emphasize the leverage BIM-based thermal analyses for the design (Welle et al., 2011). Currently, significant progress is being made in BIM common data exchange using two formats, particularly as multi-platform interoperability. Industry Foundation Class (IFC) and Green Building XML (gbXML) are two prevalent informational infrastructures in the Architecture-Engineering-Construction (AEC) industry. They are both used for common data exchange between AEC applications, such as CAD and building simulation tools (Dong et al., 2007; Knight et al., 2010). Thermal characteristic is another kind of IFC product. It is included in a sub division in another concept of basic class for physical objects, along with spatial elements, physical elements, structural analysis items, and other concepts associated with materials, shape representations, and placement in space.

After reviewing and testing some applications used to study thermal calculation and visualization, only limited tools enable us to carry out the experiment, due to its interoperability (Cormier et al., 2011; Dubois et al., 2010; Attia, 2010; Hanam, 2010; Wagner, 2010; Crawley et al., 2008). Finally, the model was carried out using Autodesk Revit and Ecotect to incorporate the design process and building performance analysis in a thermal context in order to visualize it in VE. The program enables to model the building in 3D design within the thermal simulation in IFC format. This research combines those principles to develop the method for the project experiment.

There are three steps to finalize a thermal simulation result in VE. Firstly, mockup creation in design tools (Revit). This is to get the basic shape of the building by creating a 3D model that is generated from basic data collected from the object information regarding the room measurements, material and equipment. The realistic 3D model from Revit is enriched in 3DMax. Secondly, thermal analyzing in Ecotect and thirdly, visual representation in VR tools (3DVia Studio). 


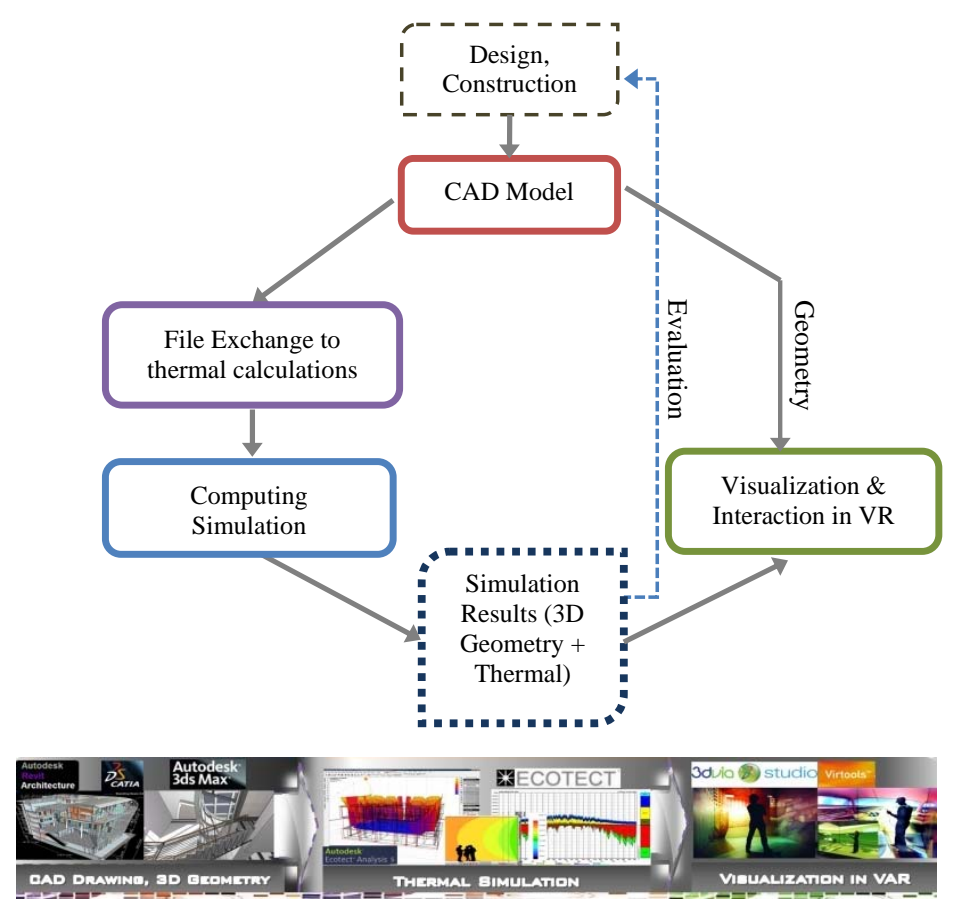

Figure 4 Illustration of data workflow for the simulation

Visualization between users and objects in a virtual world is through techniques of interaction metaphors. Metaphor in VE is a technique or paradigm, interaction method, a strategy, a scenario, allowing the user to perform a specific task in the virtual world: navigation, selecting objects, manipulating objects, controlling the application. A metaphor of interaction is used to transfer the functions. A metaphor is the transposition of an object or a concept used to facilitate the real interaction (Aguerreche et al., 2009). We develop the metaphors model based on 3D entity (i.e to represent temperature value) provided by Virtools and 3DVia Studio. It is to create an environment where the temperature data is attached in the geometry stored in the scene volumetrically. In this case, each 3D object stored inside the room has its temperature data and interacts in a set of appearance (size, shape, color, etc.). This mode of appearance then elaborates some visualization metaphors to inform the user about the thermal result interactively as well as to experience it in high immersion. To deal with the field of vision limited by screens which could interfere with the visualization, stereoscopic glasses are used which are effective in large immersive systems (CAVE).

\subsection{Technical Components, Material and Data Supply}

The experiment took place in an immersion room hosted by the Institute Image at the ENSAM ParisTech Cluny. The room is a rear-projection-based VR system, with its instruments consisting of design tools, storage, and medium of digital model presentation. The details of the instruments and how they work are as follows:

a) Software and hardware of a computer-aided design environment to create and store all necessary information about the model on computers (i.e. Autodesk Revit, Autodesk Ecotect, 3DsMax, Virtools and 3DViaStudio).

b) An input device system to enable the human user to manipulate and interact with this digital model naturally. We used a workstation equipped with monitor, keyboard, mouse, joystick, and speaker.

c) A high-fidelity output system to render and give feedback on what was created and 
manipulated in real time. The environment that our system runs on is a two-sided screen $(4 \mathrm{~m} \times 2,25 \mathrm{~m}$ each) called LITE with one projector per display. Christie Mirage HD6 DLP projector is used with $1920 \times 1080 \mathrm{HD}$ resolution. The entire system is driven by a Symmetric Multi-Processor machine with four IntelXeon E5420 2.5GHz processors, 16GB RAM, and an Nvidia GeForce GTX 260. A true three-dimensional perception is achieved using stereoscopic projection techniques. The projector supports HD active stereo, up to $120 \mathrm{~Hz}$ output.

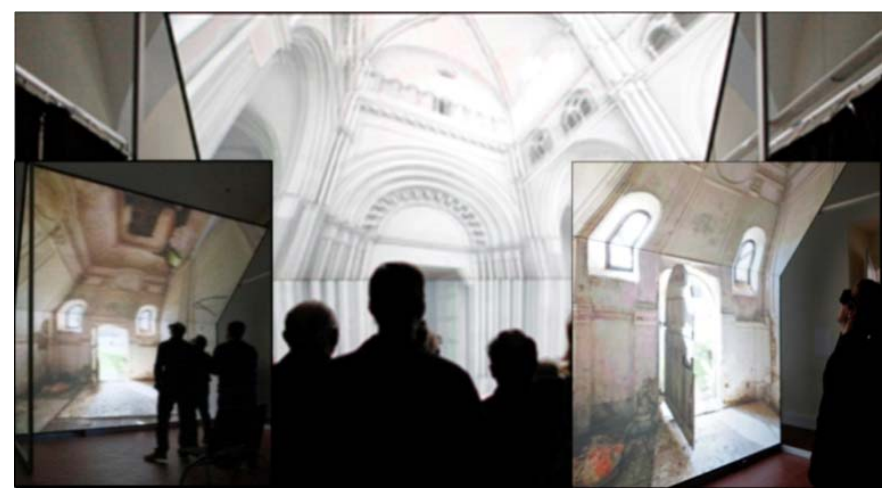

Figure 5 A view of the immersion room or LITE (Institute Image, ENSAM ParisTech Cluny)

Data exchange from Ecotect to 3DVia Studio then proceeds with exporting format Txt. However, the data tables of temperature value from Ecotect should be processed so that they can be digested directly by 3DVia Studio. This process should pass through a program (Perl Routine) that enables syntax preformat of Txt data which automatically alters the syntax typing without changing the origin data value. Txt data from Ecotect is a set of values of temperature in a 3D position (XYZ axis) to be elaborated together with the Gunzo room 3D model. These data are collected one by one according to time simulation (per hour, day and month) and this input can be detailed more precisely depending on the needs of the experiment.
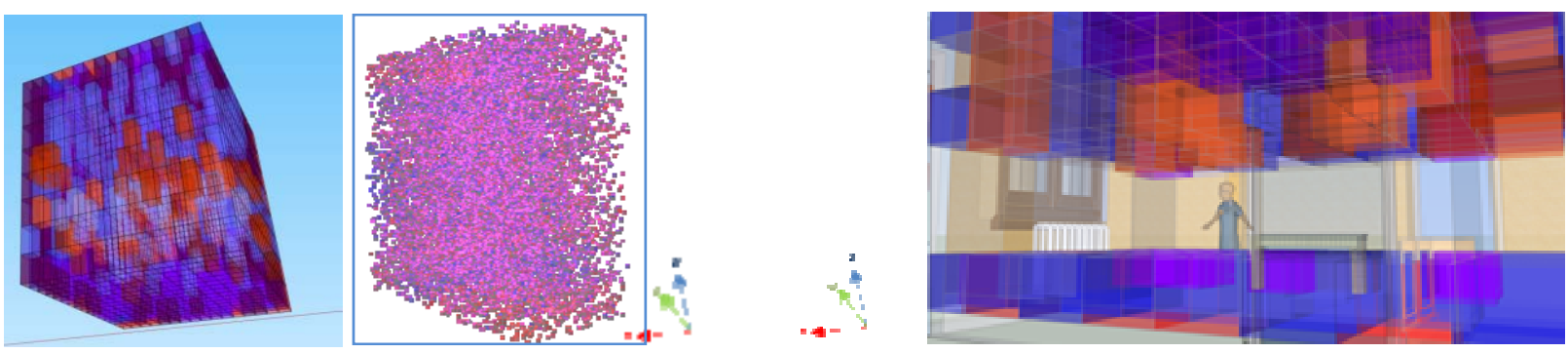

Figure 6(a) Illustration of thermal grid with transparent cubes to be generated inside the Gunzo room precisely arranged on the XYZ axis; (b) The cubes filled with particles; (c) The scenario to generate thermal visualization using grid transparent cubes

The visualization in volumetric along the $\mathrm{XYZ}$ axis is achieved through the use of building blocks and particle system in 3Dvia Studio. This system is made up of two types of objects: cubes and particles framed by the cubes. In the Gunzo room, we divide the interior space into 512 parts or small cubes (each axis divided into eight) which contains the temperature values embodied in the cubes. These 512 areas will then be used to display 4 types of graphical representations of the temperatures. Once the simulation has been updated to the current simulation time, colored cubes or particles are created at every part. They are textured in 
transparent and colored according to the temperature value it adopts. Cubes and particles are generated and updated in a similar fashion but in a different mode of visualization.

\section{RESULTS AND DISCUSSION}

\subsection{Visualization of the Simulation Results in Immersive Room}

Concerning the intrinsic nature of this system, the simulation models are split into two parts: the environment model and the entity models. The monthly temperature graph (measured by Ecotect) are preformatted into a 3D entity, transferred in VE, and displayed in four metaphors.

Table 1 Experiment with the four types of thermal metaphor

\begin{tabular}{cl}
$\begin{array}{c}\text { Type of } \\
\text { Simulation } \\
\text { Display }\end{array}$ & \multicolumn{1}{c}{ Description } \\
\hline Colored cubes & $\begin{array}{l}\text { Each of the } 512 \text { areas of the room will be occupied by a cube to which the color is } \\
\text { assigned depending on the temperature area. The transparency of the cubes can be } \\
\text { modified by the user from a small "Transparency" menu, on the right-bottom corner of } \\
\text { the display. }\end{array}$ \\
\hline $\begin{array}{c}\text { Colored } \\
\text { particles }\end{array}$ & $\begin{array}{l}\text { The cubes used in the first case will become completely transparent and will be filled } \\
\text { with small particles. The color of the particles will also depend on the temperature of } \\
\text { the area it occupies. Each particle has a life span of } 3 \text { seconds. The "life span" menu in } \\
\text { this part is used to control the number of particles in each cube. It is composed of 0-16 } \\
\text { particles in each cube. }\end{array}$ \\
\hline Layer cubes & $\begin{array}{l}\text { As mentioned earlier, the room is divided into } 8 \text { zones on each axis. In the previous } \\
\text { cases, while the room is completely filled with cubes or particles that indicate the } \\
\text { temperature of the area they occupy. In this simulation, only } 2 \text { layers are shown at a } \\
\text { time, a horizontal layer (HL) and a vertical layer (VL). } \\
\text { A "slide-in" menu is available, where the user can choose which HL or VL to be } \\
\text { displayed. It also provides an option to hide or to show the layers, and to switch } \\
\text { between displaying a simulation by cubes or particles. }\end{array}$ \\
\hline
\end{tabular}

The 3D data is attached in the geometry stored in the scene volumetrically. Each 3D object stored inside the room has its temperature data and interacts in a set of appearance (size, shape and color). This mode of appearance then elaborates the visualization metaphors with a friendly interface, to inform the user of the thermal result interactively.

In interactive simulation, the GPU calculates the resulting image of an action to send to the user visualization. It calculates and displays the result that the user asked for, depending on the action performed. In the application interface, text and 3D objects were presented together on a single display, as a hybrid representation, for the situations where multiple cognitive channels need to be provided. Visualization between users and objects in a virtual world are certainly through techniques of interaction metaphors. The application prototype provides an instrument of visualization and interaction in VE, including friendly interface concerning the thermal condition. The interface is designed in such a way that the user can immerge, interact, and perceive the impact of the modifications generated by the system regarding the thermal simulation results. 


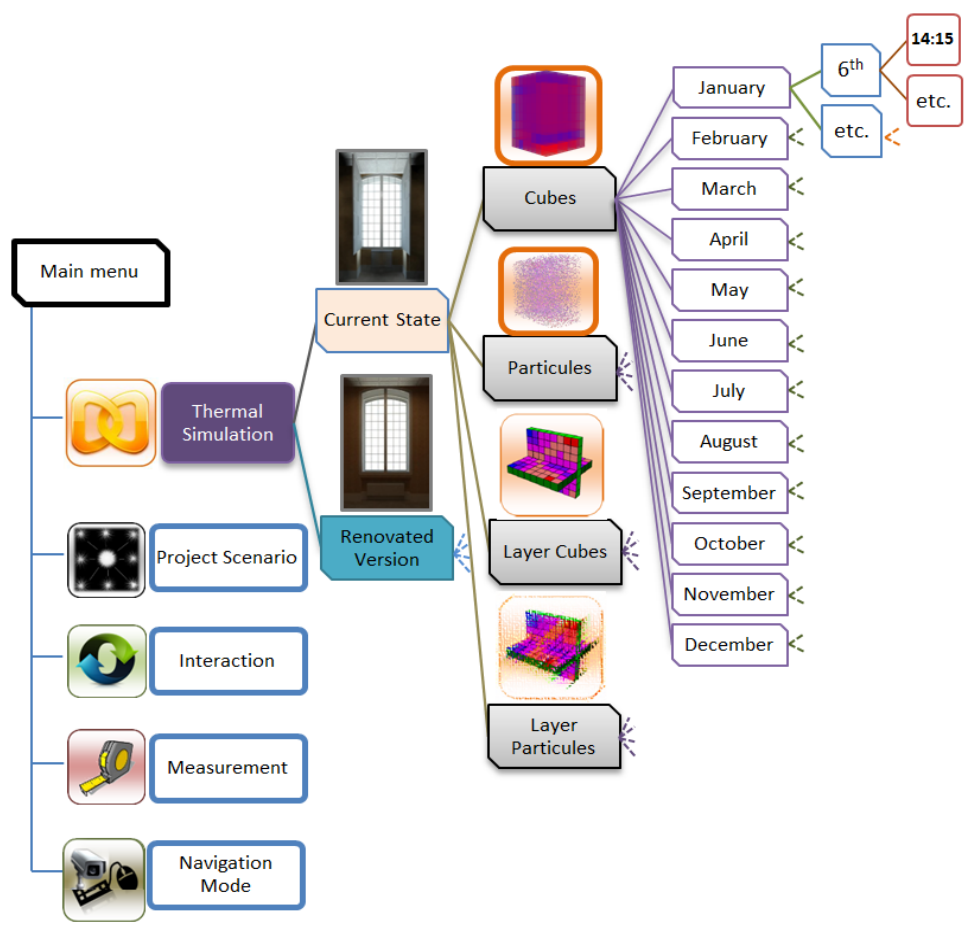

Figure 7 Principle of system commands and menus for the user interface

Some menus and sliders are used to select and to manipulate the objects, as well as to explore the simulation results. The main menus display the type of simulation and the simulation time. Both the Gunzo room in existing conditions and renovated versions were processed in this time simulation to make comparisons. The user is equipped with a pointing device or joystick allowing him/her to change some settings. A navigation mode is defined for exploration, search tasks and manoeuvring tasks. The user can move within the room by selecting a predefined view from a list. These views are represented by items in the room or thumbnails. The user can also move within the room using the pointing device.

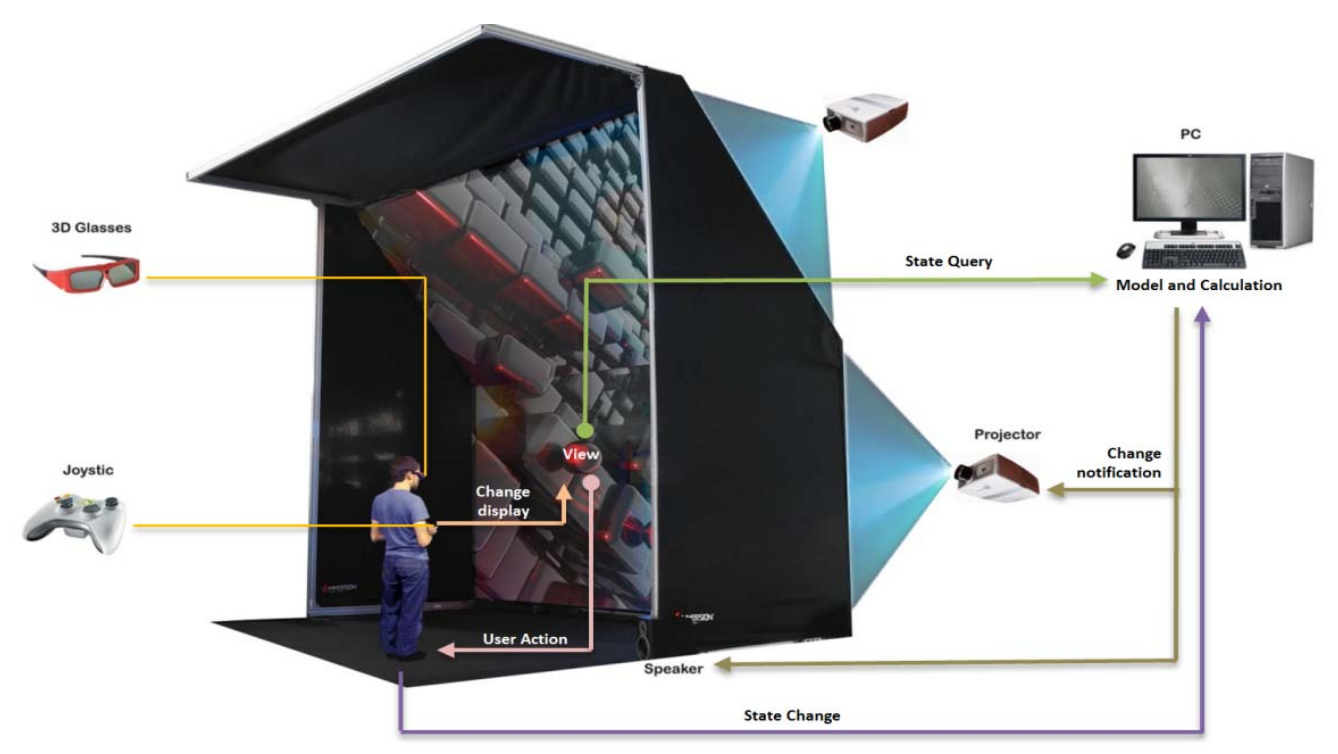

Figure 8 The instruments and system of the interface within the immersion room. 
The coupling is flexible between the three blocks: Model, View and Controller. This implies that the change of a block does not affect the overall structure, which makes changes easier. Thus, the user can immerge, interact, and perceive the impact of the modifications generated by the system.

In the experiment, some participants have invited to experience the simulation and have recorded their responses and opinions in a structured questionnaire.
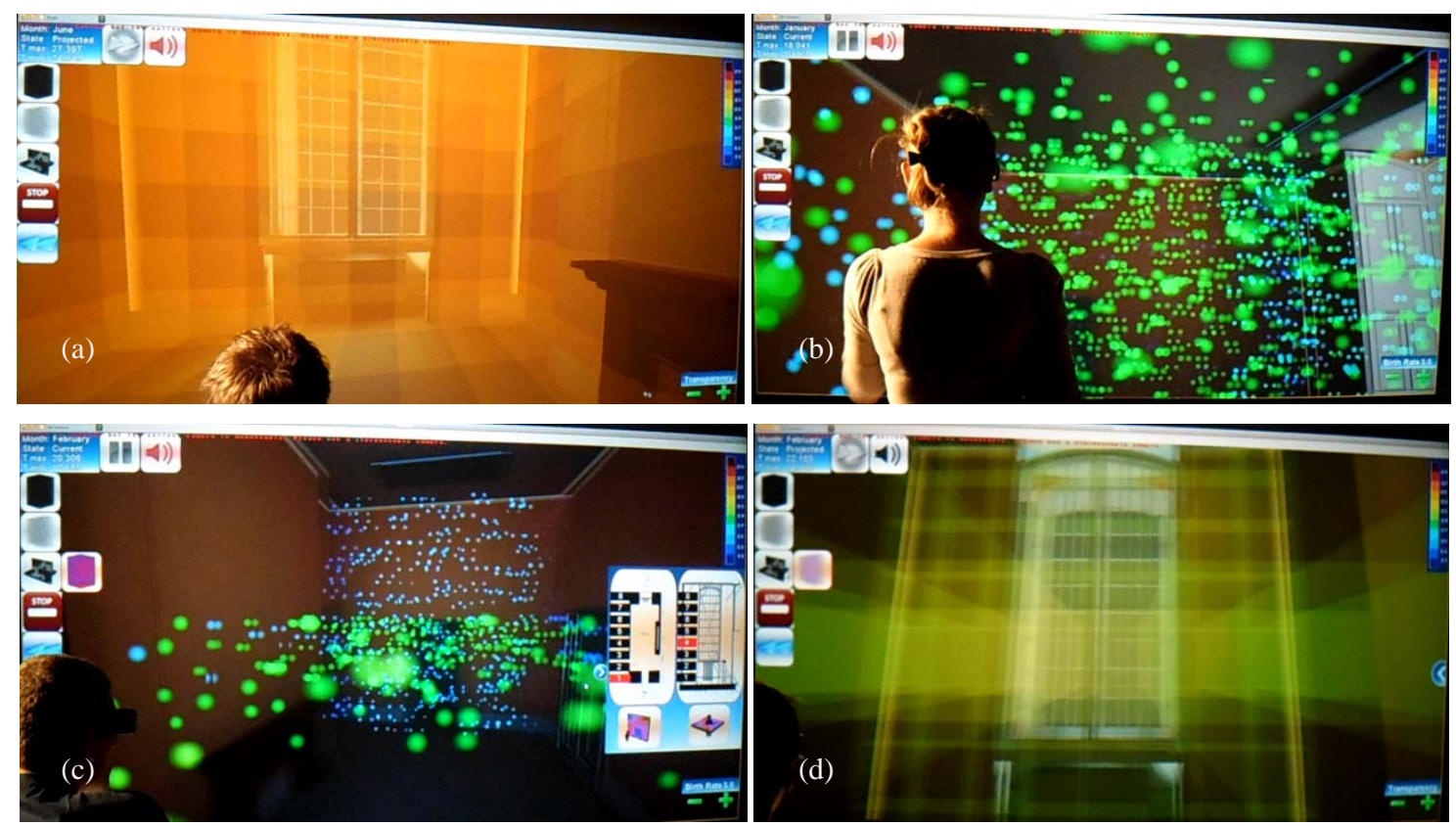

Figure 9 Thermal metaphors of transparent cubes and particles simulated in the immersion room with stereoscopic visualization tested by some participants; (a) Simulation results of renovated version in June 6th,14:15 with colored cubes; (b) Simulation results of the Gunzo room in existing conditions in January, using particles; (c) Simulation results on February 6th,14:15, using layer particles in vertical and horizontal; (d) Simulation results of the renovated version using layer cubes in vertical and horizontal on March 6th, at 14:15

\section{CONCLUSION}

The paper describes the development of an application to visualize thermal data for building energy efficiency in a VE. The application has managed to show the simulation results of thermal data mainly operated in the immersion room. It shows that the use of the data workflow and the thermal metaphors can improve interaction with the simulation and immersion in VE. It also has interaction techniques that assist in visualization and simulation in full immersiveness. Some previous works have suggested such approaches but they are not quite optimized in interaction and immersion with an advanced interface. Our method in this context provides both system and workflow concepts for visual representation of thermal data to easy facilitate the general user. The method is very effective as it can deliver the real atmosphere of a room before and after construction in an immersive room. As the application should be flexible to all building stakeholders, we found that its workability should emphasize effectiveness in terms of precision. However, as the application should be flexible in various thermal building simulation tasks, it still has issues on effectiveness in terms of immersiveness and interactiveness.

Technical drawings and explanatory texts are often insufficient in fully comprehending a 3D object and its thermal calculation result. In the experiment, the user has the ability to compare temperatures corresponding to different settings of the VE, to interact with it, change its 
characteristics and perceive the impact of their actions. The system enables the user to interact with the VE intuitively while assessing the comfort/discomfort of the thermal settings of the room.

In fact, the simulation of the thermal result can be easily delivered within a VR environment, since the user can learn the effects of the controls in the VE. This indicates the potential to adapt the system easily.

Obviously, in order to improve the overall availability, the interoperability between software and the quality of the user interaction with the virtual prototype are crucially important. For future research, we suggest to set the thermal simulation result and the VE automatically in a high interoperability. The application also needs to be equipped with some tools to present the impact of thermal changes made directly by the user on the visualization system and to improve the technical services offered by software platforms.

\section{ACKNOWLEDGEMENT}

The authors are grateful to the Direktorat Riset dan Pengabdian Masyarakat (DRPM) Universitas Indonesia for the financing support under Research Grant No. 2191/H2.R12/HKP.05.00/2012, and the valuable comments of the reviewers.

\section{REFERENCES}

Aguerreche L, Duval T, Arnaldi B., 2009. Analyse de Techniques de Coopération en Environnements Virtuels 3D, RSTI - TSI. Réalités virtuelle et augmentée Volume 28, pp. 763-793

Atmaca, I., Kaynakli, O., Yigit, A., 2006. Effects of Radiant Temperature on Thermal Comfort, ScienceDirect - Journal Building and Environment, Elsevier Volume 42, pp. 3210-3220

Attia, S., 2010. Building Performance Simulation Tools: Selection Criteria and User Survey. Research Based Report. Architecture et climat, Université catholique de Louvain, Louvain La Neuve, Belgium, pp. 14-27

Bean, R., 2010. Mean Radiant Temperature (MRT), Available online at http://www.healthyheating.com/Definitions/Mean Radiant.htm\#.UTB1sFcySpA (Accessed on 23 January 2013)

Bruno, F., Caruso, F., Li, K., Milite, A., Muzzupappa, M., 2008. Dynamic Simulation of Virtual Prototypes in Immersive Environment, Journal of Advance Manufacture Technology Springer Volume 43, pp. 620-630

Clifton, M., Pang, A., 1997. Cutting Planes and Beyond. Journal Computer \& Graphics Elsevier Volume 21(5), pp. 563-575

Cormier, A., Robert, S., Roger, P., Stephan, L., Wurtz, E., 2011. Towards a BIM-based Service Oriented Platform: Application to Building Energy Performance Simulation. 12th Conference of International Building Performance Simulation Association, Sydney, pp. 2309-2316

Crawley, D.B., Hand, J.W., Kummert, M., Griffith, B.T., 2008. Contrasting the Capabilities of Building Energy Performance Simulation Programs. Journal Building and Environment Elsevier, Volume 43, pp. 661-673

Dubois, M.C., Horvat, M., 2010. State-of-the-art of Digital Tools Used by Architects for Solar Design. IEA SHC Task 41 - Solar Energy and Architecture, Subtask B - Methods and Tools for Solar Design, pp.22-115

Dong, B., Lam, K.P., Huang, Y.C., Dobbs, G.M., 2007. A Comparative Study of the IFC and gbXML Informational Infrastructures for Data Exchange in Computational Design Support Environments. Proceedings: Building Simulation, pp. 1530-1537 
EERE (Energy Efficiency and Renewable Energy), US Department of Energy. Availabel ate http://apps1.eere.energy.gov/buildings/energyplus/weatherdata_about.cfm? (Accessed: 10 December 2012)

Fricoteaux, L., 2010. Conception d'un Environnement Virtuel Informé: Application à la Restitution de Calculs Scientifiques. Rapport d'activités Stage TN10/ST02, l’Université de Technologie de Compiègne, France

Gutierrez, M., Vexo, F., Thalmann, D., 2008. Stepping into Virtual Reality. Springer, London

Hanam, B., 2010. Development of an Open Source Hourly Building Energy Modeling Software Tool. Thesis Master of Applied Science in Civil Engineering, University of Waterloo, Ontario, Canada, pp. 9-55

Humphreys, M.A., Nicol, J.F., 1998. Understanding the Adaptive Approach to Thermal Comfort. ASHRAE Transactions, Volume 104 (1), pp. 991-1004

Knight, D., Roth, S., Rosen, S.L., 2010. Using BIM in HVAC Design. ASHRAE Journal, Volume 52(6),pp 24-32

Malkawi, A.M., Srinivasan, R.S., 2005. A New Paradigm for Human-Building Interaction: The Use of CFD and Augmented Reality, Volume 14(1), pp. 71-84

Ter Minassian, H., 2011, La réhabilitation thermique des bâtiments anciens à Paris: comment concilier protection du patrimoine et performance énergétique? Cybergeo: European Journal of Geography, Aménagement, Urbanisme, article 536, 2011. Available online at http://cybergeo.revues.org/23737 (Accessed: 21 January 2013)

US GSA, Statsbygg and Senate, 2010. Information Delivery Manual (IDM) for BIM Based Energy Analysis as Part of the Concept Design BIM

Van Treeck, C., Petra, W., Andre, B., Michael, P., Martin, E., Oliver, W., Ernst, R., 2006. Towards Interactive Indoor Thermal Comfort Simulation, European Conference on Computational Fluid Dynamics ECCOMAS CFD

Wagner, A.D., 2010. Revit Architecture+Ecotect.BIM/CAD Camp 2010, US CAD Honolulu Hawai. Available online at www.uscad.com ; www.uscadbim.com (Accessed: 22 January 2013)

Welle, B., Haymaker, J., Rogers, Z., 2011. ThermalOpt: A Methodology for Automated BIMbased Multidisciplinary Thermal Simulation for Use in Optimization Environments, Building Simulation-Tsinghua University Press and Springer-Verlag Berlin Heidelberg 4, pp. 293-313

Woksepp, S., Olofsson, T., 2006. Using Virtual Reality in a Large-scale Industry Project. Journal ITcon, Volume 11, pp. 627-640 